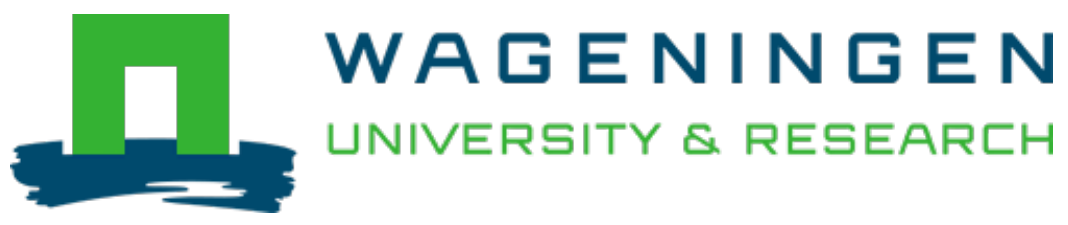

\title{
To Stay or Not to Stay? Artificial Sociality in GRASP World
}

\author{
Advances in Social Simulation
}

Hofstede, Gert Jan; Liu, Chutao

https://doi.org/10.1007/978-3-030-34127-5 20

This article is made publicly available in the institutional repository of Wageningen University and Research, under the terms of article $25 \mathrm{fa}$ of the Dutch Copyright Act, also known as the Amendment Taverne. This has been done with explicit consent by the author.

Article $25 \mathrm{fa}$ states that the author of a short scientific work funded either wholly or partially by Dutch public funds is entitled to make that work publicly available for no consideration following a reasonable period of time after the work was first published, provided that clear reference is made to the source of the first publication of the work.

This publication is distributed under The Association of Universities in the Netherlands (VSNU) 'Article $25 \mathrm{fa}$ implementation' project. In this project research outputs of researchers employed by Dutch Universities that comply with the legal requirements of Article $25 \mathrm{fa}$ of the Dutch Copyright Act are distributed online and free of cost or other barriers in institutional repositories. Research outputs are distributed six months after their first online publication in the original published version and with proper attribution to the source of the original publication.

You are permitted to download and use the publication for personal purposes. All rights remain with the author(s) and / or copyright owner(s) of this work. Any use of the publication or parts of it other than authorised under article $25 \mathrm{fa}$ of the Dutch Copyright act is prohibited. Wageningen University \& Research and the author(s) of this publication shall not be held responsible or liable for any damages resulting from your (re)use of this publication.

For questions regarding the public availability of this article please contact openscience.library@wur.nl 


\title{
Chapter 20 \\ To Stay or Not to Stay? Artificial Sociality in GRASP World
}

\author{
Gert Jan Hofstede and Chutao Liu
}

\begin{abstract}
This paper describes an agent-based model that investigates group longevity in a population in a foundational way, using theory on social relations and culture. The model is the first application of the GRASP meta-model for social agents, containing elements of Groups, Rituals, Affiliation, Status and Power. It can be considered an exercise in artificial sociality: a culture-general, content-free baseline trust model from which to engage in more specific studies. Depending on cultural settings for individualism and power distance, as well as settings for xenophobia and for the increase of trust over group life, the GRASP world model generates a variety of patterns. Number of groups ranges from one to many, composition from random to segregated and pattern genesis from rapid to many hundreds of time steps. Parallels are discussed between patterns found in GRASP world and patterns found in societies that differ on individualism, power distance and heterogeneity.
\end{abstract}

Keywords Culture · Individualism · Power distance · Uncertainty avoidance · Xenophobia · Agent-based model · GRASP · Status-power theory · Artificial sociality

\section{G. J. Hofstede $(\bowtie)$}

Social Sciences, Information Technology, Wageningen University, Hollandseweg, The Netherlands

UARM, North-West University, South Africa

e-mail: gertjan.hofstede@wur.nl

C. Liu

Social Sciences, Information Technology, Wageningen University, Hollandseweg,

The Netherlands

e-mail: chutao.liu@wur.nl 


\subsection{Introduction}

Issues of group cohesion are being studied in various fields and at various scales: mergers and acquisitions, small group dynamics, organizational behaviour, conflict management, politics, geopolitics, etc. In this paper we look for common ground between all of these domains. We aim for a bottom-up way of growing groups and modelling their composition and existence through time, using the technique of agent-based modelling. Our self-confidence for attempting such a generic model is based in empirics: the cultural differences found across the world that touch all walks of life in a society, from the family to the school, workplace and political arena [1]. However, below culture there is another layer: relational life [2]. Our agents need relational motivations. I call this relational logic in agent-based models 'artificial sociality', a term coined by Gilbert and Conte [3]. In artificial sociality, both individual motives, formal social structure and cultural 'unwritten rules' matter. Cross-cultural issues turn out to be important in many socio-technical systems, because they imply different unwritten rules of the social game [1] and therefore different norms and values. When people differ in their values, norms, beliefs and rituals, but have to collaborate in a single technical environment, or using a single formal organizational structure, misunderstandings that lead to malfunctioning systems are very likely. Real life abounds with examples about the unanticipated side effects of changes in technology or in policy. Examples in socio-ecological systems include unintended pollution or environmental degradation. In sociotechnical systems, they include altered opinion dynamics in networks dominated by social media versus face-to-face interaction. For instance, social media are changing opinion dynamics, while culture also shapes social media usage [4].

We draw our agents' relational drives from Kemper's generic status-power theory [5]. Since this is the first implementation of such a model, and truth emerges more readily from error than from confusion, it is kept very simple; our hope is that others will take these ideas further. While the thinking behind GRASP is available [6], implementations are not. This is why the theory development covers a bit more ground than the implemented model; it shows potential areas for development of GRASP world. Still, we omit important areas: there are no content issues, no cognitive complexity of individuals, no cross-group status-power relations and no evolution.

As far as we know, GRASP world is the first model of its kind. It is close to abstract social models that rely on a limited set of concepts and mechanisms for modelling emergence of system-level pattern, e.g [7-9]. It differs in its reliance on existing social science theory. GRASP paints with a slightly finer brush, trying to add cultural variation to a model that is generic across all people. It does not pretend to be anything more than a first attempt. This means that no validation beyond plausibility is possible. Any real-world application will contain features that are absent from GRASP world, which could affect the dynamics. 


\subsubsection{To Stay or Not to Stay?}

To resolve collective action issues, actors frequently have to invest effort in cooperation. The willingness of actors to cooperate is strongly related to their expectations about whether others will cooperate [10]. The absence of trust leads to lines of reasoning such as 'if I preserve this common resource, someone else will take it, so I might as well take it myself'. This could lead to a vicious circle. Partners would then be forced to either stop collaborating altogether or try to subdue others into compliance.

People do not just engage in collective action with anyone; they can choose their partners to some extent, for instance, within a fixed in-group. A second mechanism is that people can negotiate the extent of their pro-social behaviour in promises or contracts and thus voluntarily mutually expose themselves to compliance. This is what happens in a commons [11], avoiding the selfish overconsumption that results in a 'tragedy of the commons'.

How do actors know whether they have the right partner? Perhaps their most crucial option, relying on their experience, is leaving a bad partner or group. This is the main focus of the model to be discussed here. Often the question of whether to stay with a group is framed as 'trust', certainly in individualistic cultures, where changes in group membership are frequent. However, trust is a multifaceted phenomenon, and its meaning could vary across cultures [12]. GRASP world is naive about the question whether the agents themselves would think of 'trust'. Neither does it model any shareable resources. Only the agents' action counts: they leave, or they stay. How difficult this decision is, many readers will know from their own experience in jobs or personal relationships. At the level of nations, it is apparent from issues such as boundaries and fission and fusion dynamics between empires and states. As an illustration, consider the history of Europe, with EU membership being the latest in an endless succession of changes.

This first implementation of GRASP world uses the main GRASP components (Groups, Rituals, Affiliation, Status, Power). Agents need the following:

- A motive for gathering in various groups (Groups, Affiliation)

- A way of conferring status (in this case a content-free mutual exchange of status; Ritual, Status)

- A motive for leaving a group (being 'unhappy': receiving less status than one deems oneself worthy of; this motivates an agent to search for alternative groups that might confer more Status)

- A way of settling a status offence (picking a fight: Power contest). The outcome changes their social status: the winner gains status, the loser goes down in status (as in Hemelrijk's DomWorld; see [9, 13]).

Additionally, GRASP world contains constructs for dealing with culture and trust in the simplest ways, discussed below. These modify the strengths of the motives. 


\subsubsection{Groups Across Cultures}

The organization of society into groups and institutions, companies and governments differs across cultures. This depends on many factors, of which in GRASP world only culture remains, since its world is undifferentiated. For a bird's eye perspective on culture, we take Hofstede's model with its six dimensions: individualism, power distance, masculinity, uncertainty avoidance, long-term orientation and indulgence. Two of these are of obvious relevance for the probability of leaving a group. These are individualism and power distance [1, 14]. Other dimensions may play a role too; of these we shall discuss uncertainty avoidance in the context of xenophobia and familiarity.

A society's individualism is a measure of the independence of individuals. It ranges from voluntarist, often volatile relationships in individualistic societies, versus life-long interdependence of group members in collectivistic ones. In the former case, leaving a group is easy; in the latter, it is almost impossible.

A society's power distance has to do with acceptance of differences in social status and power. In a hierarchical (i.e. with large power distance) culture, individuals that receive less status are likely to accept this as natural. Powerful members in societies of large power distance also feel entitled to using their power: 'might makes right'. Thus, in a culture of large power distance, those who receive less status are likely to accept this and not have a motive for leaving the group. They might wish to leave in their hearts, but not feel empowered to do so; or they might simply not consider the option. In an egalitarian (i.e. with small power distance) culture, everyone is empowered to decide for themselves.

The plausibility of these ideas is corroborated by cross-cultural comparative findings. We shall mention a few across domains. This also makes the point that GRASP world is applicable across many application domains.

Consider, e.g. Fig. 4.1 in Hofstede, Hofstede and Minkov [1] that plots countries on the dimensions of individualism against power distance. Countries with open political systems that change smoothly over time are concentrated on the side of egalitarian, individualistic cultures. Countries with long-standing regimes interspersed with revolutions are found on the side of large power distance and collectivism. Or consider the findings on consumer behaviour in de Mooij [15], who found, e.g. a strong relationship across EU countries between collectivism and brand loyalty. Trying a new brand apparently has a connotation of leaving one's group.

A more proximate phenomenon is the behaviour of tourists or reception guests in multinational settings. Those from more collectivistic cultures are more likely to be found in in-group clusters.

The fact that differences in group behaviour are culture-mediated is also borne out by studies among children showing that for them too, the probability of leaving a group varies with individualism and power distance [16, 17]. 
Table 20.1 Hypothesized sources of continued group membership according to culture

\begin{tabular}{l|l|l|l}
\hline & & Individualism & Collectivistic \\
\cline { 3 - 4 } & & Individualistic & $\begin{array}{l}\text { Identification } \\
\text { Kinship } \\
\text { Power distance }\end{array}$ \\
& Small & $\begin{array}{l}\text { Bonus schemes, certification, } \\
\text { contract, empathy, legal } \\
\text { enforcement, monitoring, perceived } \\
\text { match, price premiums, social } \\
\text { norms, transparency }\end{array}$ & $\begin{array}{l}\text { Perceived match } \\
\text { Reputation } \\
\text { Social norms }\end{array}$ \\
\cline { 2 - 4 } & Large & $\begin{array}{l}\text { Dependence, hierarchy, honour, } \\
\text { sense of duty, social norms }\end{array}$ & $\begin{array}{l}\text { Allegiance, hierarchy, } \\
\text { kinship, reputation, sense of } \\
\text { duty, social norms }\end{array}$ \\
\hline
\end{tabular}

\subsubsection{Trust Across Cultures: Individualism and Power Distance}

In collectivistic cultural settings, trust in formal, impersonal institutions tends to be low [1]. Instead, sources of trust are found in the relationship in the in-group or in informal institutions such as norms. If the societal context is also hierarchical, implicit hierarchy will determine loyalties.

In individualistic societies, everybody is a priori supposed to be equally trustworthy. Trust can be based on incentive control or on positive emotions. Impartial third parties and institutions will be accepted, especially if the society is also egalitarian. If the society is also hierarchical, a sense of filial duty could play a role.

A cross-European study on trust placed in sellers in food supply networks [12] yielded a typology that is useful for our purposes. The typology was inspired by Nooteboom [18]. It opens the way to a discussion of relationships between trust and the culture-bound organization of society. Table 20.1 is based on it, with additions. It shows that many of the contemporary trust mechanisms such as contracts fit an individualistic, egalitarian culture that describes the prototypical Western, highly institutionalized society. To the extent that the society is less egalitarian and more collectivistic, other forms of trust enforcement will be important in practice, even if they are not codified in laws. Social norms exist everywhere, only not the same ones.

Table 20.1 uses term charged with content matter. In our GRASP world, there is no content. Therefore, we 'zoom out', leaving only the most basic feeling of 'happiness'. This is meant in Kemper's sense as 'having received appropriate status'. The various sources of trust from Table 20.1 are collapsed onto agent 'happiness'. Table 20.2 shows the influence of individualism and power distance on leaving a group in GRASP world. 
Table 20.2 Reasons for leaving a group depending on individualism and power distance. A 'big shot' is the group member with the most social status, if above one's own

\begin{tabular}{l|l|l|l}
\hline & & Individualism & \\
\cline { 3 - 4 } & & Individualistic & Collectivistic \\
\hline \multirow{2}{*}{ Power distance } & Small & Leave if unhappy & Leave if very unhappy \\
\cline { 2 - 4 } & Large & Leave if unhappy and no 'big shot' present & Do not leave \\
\hline
\end{tabular}

\subsubsection{Social Identity, Xenophobia and Familiarity, and Uncertainty Avoidance}

Trust is related to social identity and shared practices [19]. Predictable behaviour by others and trust in them go hand in hand. This is observed even in individualistic societies or in mixed-culture settings: one tends to trust people of the same social identity, regardless of the culture that they might have. The difference is that social identity is visible on the outside, while culture is not.

The dimension of culture Uncertainty Avoidance is relevant here. An uncertainty avoiding culture is one in which people feel anxious in situations that they are unfamiliar with. This has the effect of making them slow to adopt unpredictable changes, such as accepting members from unfamiliar groups, and more rigid in their rituals. Strong uncertainty avoidance in a society is associated with distrust of strangers and love of familiar ritual. For the dynamics of trust in a group, the above means that people could be expected to become less likely to leave a group the longer they have already been in it. This effect should be stronger in more uncertainty avoiding societies, where familiarity is more strongly reassuring [1] (Chap. 6). Still, these two trust-related aspects of group life (xenophobia and familiarity) are conceptually distinct. We shall take them both on board separately.

To model xenophobia we introduce a simple scalar parameter that denotes different practices or social identities, visible to outsiders. In the real world, one could think of hairstyle, colour, clothing, greetings, food habits and so forth. We call it 'norm meme' for 'Nexus of Relational Memes'. The acronym 'norm' could be confusing, and neither 'social identity' nor 'practice' fit the bill, so we refer to it as 'shade', since agents' shade is its visible form in the interface. In any of the quadrants of Table 20.2, xenophobia could lead to two potentially opposing trends. If we have a homogeneous society, uncertainty avoidance could be associated with smoothly oiled operations in which all take pride in being predictable. If, on the other hand, we have a heterogeneous society with varying practices and social identities, xenophobia could be associated with segregation along the lines of differences in behaviour or in visible group affiliation.

Familiarity depends on experience in a group. Agents only interact within their group, until they leave it and join a random other agent or group. Agents in a group acquire the same 'aura' colour. Depending on the weight of the parameter 'dyadictrust-factor', groups can generate familiarity-based trust, making their members progressively less likely to leave. 


\subsection{The Model: GRASP World}

\subsubsection{Description}

For reasons of space, the following more technical description is incomplete; more details can be obtained from the authors. GRASP world is built with NetLogo (Wilensky 1999, version 6.0.2) and is available on COMSES [20], including an ODD + D description [21]. Model interface is shown in Fig. 20.1. Space limitations prohibit showing the details in this chapter.

Agents with different shades randomly scatter on an undifferentiated ground. One tick represents one time of interaction, and simulation is run for 1000 ticks. The length of a tick is deliberately undefined. It could be a second, and the simulation could show a schoolyard or a reception. It could be a year, and the simulation could represent a political landscape or a social network. For each tick, each individual goes through the process 'Play with group mate', during which an individual and his/her communication partner for this tick confer status to each other and perceive status affront. This mutual status-conferral and perception process affects the pair's emotions ('happy', 'neutral' or 'angry') and consequently influences the group dynamics.

The status conferral for each is determined by picking a random number from a normal distribution with a mean of 0.5 and a standard deviation set by 'statusconferral-stdev'. Perceived status affront is calculated as follows ('my' and 'mate' symmetrical):
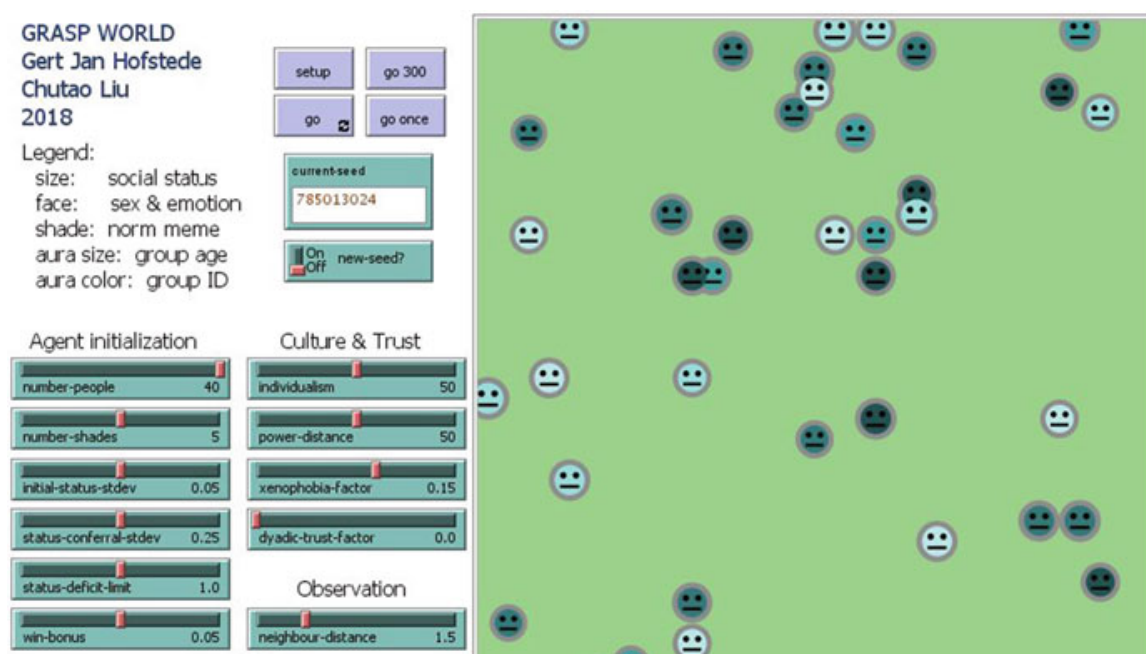

Culture \& Trust
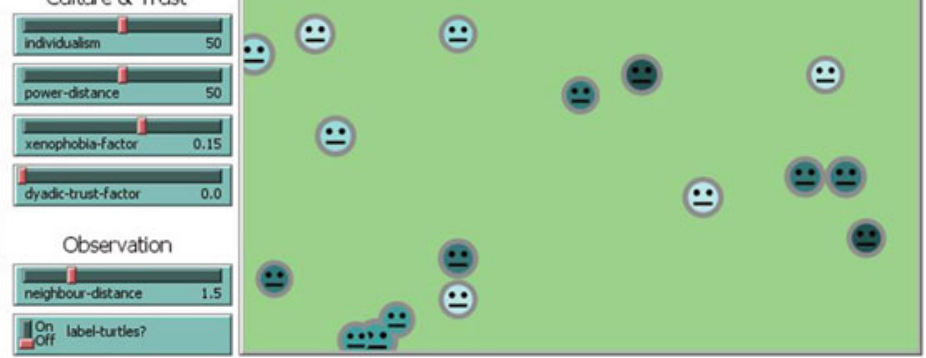

Fig. 20.1 Model interface at $t=0$. All agents have equal status indicated by avatar size, and there are five shades 


$$
\begin{aligned}
& \text { My - perceived - status - affront } \\
& =\text { (my-status-conferral-mate-status-conferral) } \\
& \text { + norm-misunderstanding-submission-dyadic-trust. }
\end{aligned}
$$

where

Norm-misunderstanding $=$ xenophobia-factor $* \mid$ my-shade - mate-shade $\mid$

Submission $=$ power-distance $/ 100 *$ (mate-status - my-status $)$

Dyadic-trust $=($ dyadic-trust-factor $/ 10) *$ time-in-group-together

For the 'decide to leave or not' process, the group member with highest status ('bigshot') will decide first. The decision mechanism is the same for everyone and is based on individualism, person's own emotion and other group members' emotions. If the bigshot decides to leave the group, then other 'ordinary' members in the group can make their decisions and leave as they want. If the bigshot decides to stay, then other members have to overcome their submission to the bigshot to be entitled to leave. The group will be dismissed if less than two members remain.

\subsubsection{Model Analysis}

Sensitivity analysis was performed using one-factor-at-a-time method (OFAT) on all parameters, with non-varied variables at default value. Due to limited space, we present only the two most sensitive ones. Number of groups and status distribution (standard deviation) among agents are selected as outcomes. Their sensitivity to xenophobia-factor (with a population consisting of 5 norm shades) and dyadic-trustfactor are presented in Figs. 20.2 and 20.3, respectively.
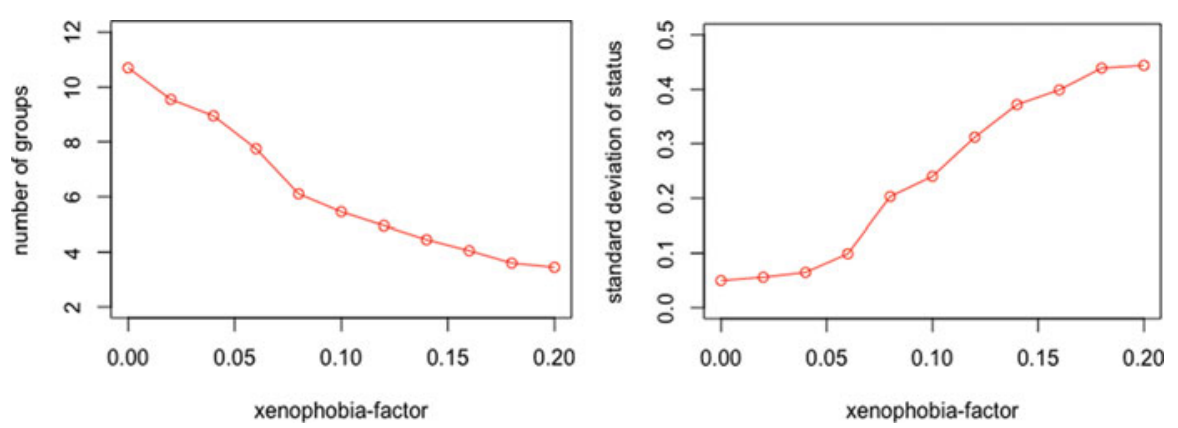

Fig. 20.2 The sensitivity of 'number of groups' (left) and 'standard deviation of status among agents' (right) to xenophobia-factor. Each data point is the average value of 20 repetition runs of 1000 ticks at corresponding parameter settings 

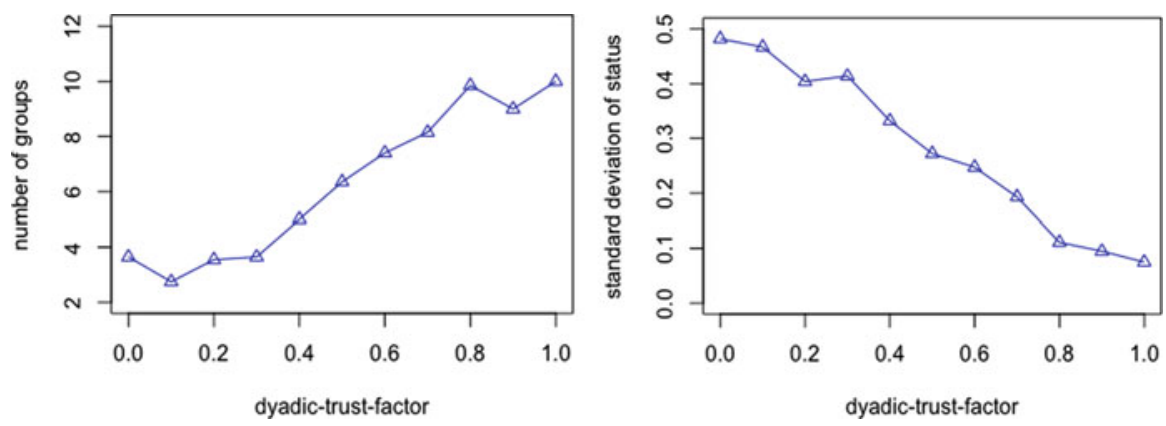

Fig. 20.3 The sensitivity of 'number of groups' (left) and 'standard deviation of status among agents' (right) to dyadic-trust-factor. Each data point is the average value of 20 repetition runs of 1000 ticks at corresponding parameter settings

Table 20.3 Results across culture in the absence of xenophobia

\begin{tabular}{l|l|l|l}
\hline & & Individualism & Collectivistic \\
\cline { 3 - 4 } & Individualistic & $\begin{array}{l}\text { Many stable happy } \\
\text { groups }\end{array}$ \\
\hline Power distance & Small & One happy group & $\begin{array}{l}\text { Many stable groups } \\
\text { with infighting }\end{array}$ \\
\cline { 2 - 4 } & Large & $\begin{array}{l}\text { One group with status fights that can } \\
\text { break up ultimately after }>1000 \text { ticks }\end{array}$ &
\end{tabular}

Both outcomes are sensitive to xenophobia-factor and dyadic-trust-factor. The increase in xenophobia leads to fewer groups and more obvious status differentiation. Since xenophobia positively contributes to agents' perceived status affront, higher xenophobia-factor will cause more fights and consequently lower group stability. Under frequent fights, winners are able to accumulate high status, while losers tend to be suppressed over time, which intensifies status differentiation. In contrast, higher dyadic-trust-factor reduces the possibility of fights and thus stabilizes groups. When dyadic trust is high, nearly no fights break out and agents seldom gain or lose status during their interactions with each other. Hence, the status differentiation and model dynamics in general are less with higher dyadic-trustfactor.

\subsubsection{Model Results}

Table 20.3 gives the trends observed when only considering individualism and power distance. Since tick 1 always yields a large number of small groups, which may or may not evolve subsequently, Table 20.3 shows that ability to leave boosts evolution of groups. Xenophobia leads to more fighting if there are different shades, while in combination with dyadic-trust, it can still yield stable, usually shadesegregated groups. 

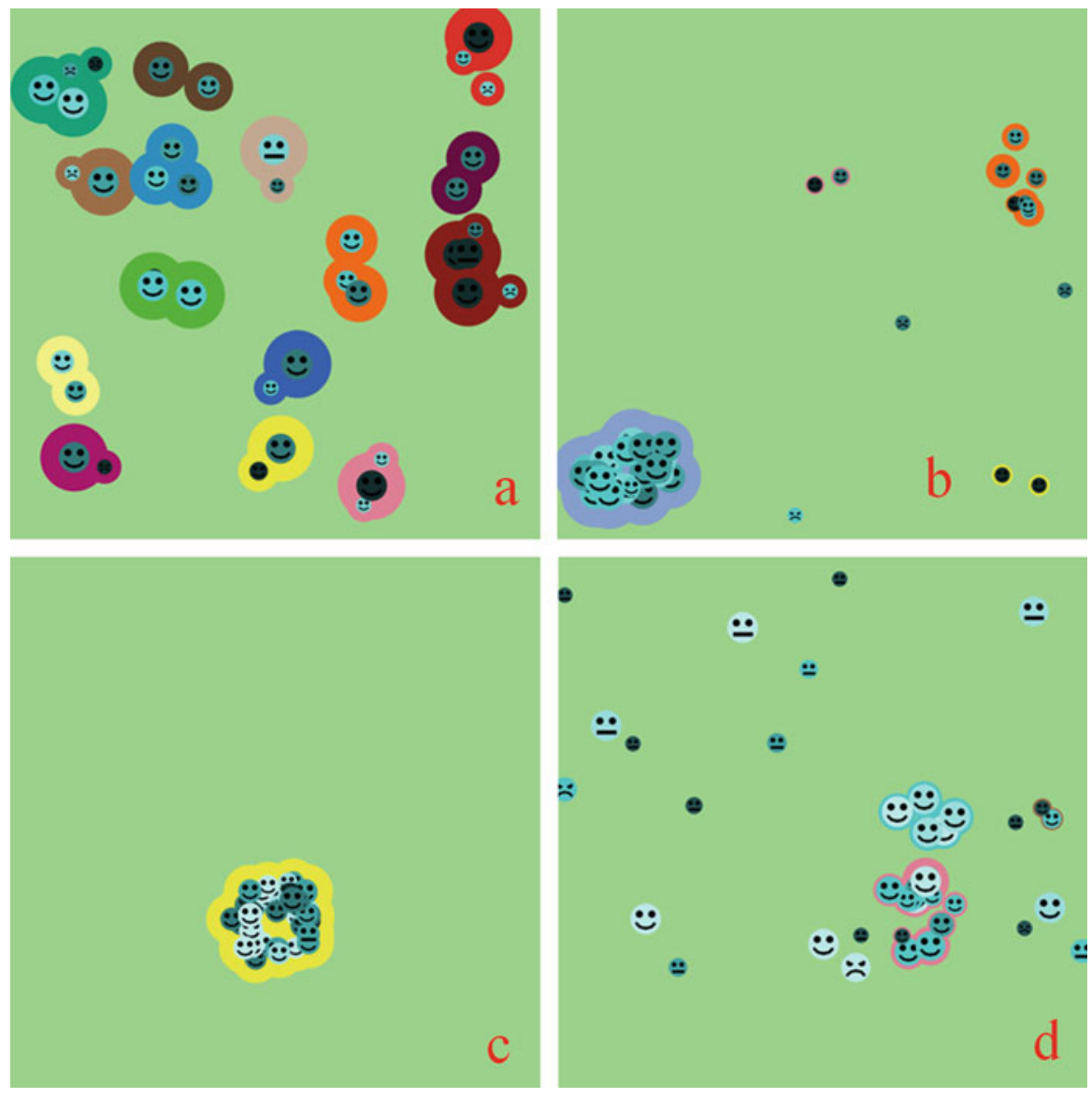

Fig. 20.4 (a-d) Group dynamics at $t=1000$ under different parameter settings. The aura around the individuals marks their group. Individuals with same aura colour are in the same group. The longer an agent stays in a group, the larger its aura size grows, until 20 ticks. Individuals with no auras are alone at the moment

Depending on the settings of trust-factor, xenophobia-factor and the two cultural factors and the shades, a number of patterns can occur. Some are stable; some show periodic upheaval. We show five of these patterns in Figs. 20.4a-d and 20.5. All non-mentioned parameters are at their defaults.

- Pattern 6a: low individualism (10), large power distance (90), no xenophobia, no dyadic-trust

- Pattern 6b: high individualism (90), large power distance (90), no xenophobia, no dyadic-trust

- Pattern 6c: high individualism (90), medium power distance (50), no xenophobia, no dyadic-trust 
Fig. 20.5 Pattern e, Happy

Segregation. The picture shows part of the interface at $t=600$. This population with two widely different norm shade subpopulations self-organizes into a segregated system, with usually two groups per shade, agents staying in a group for more than 40 ticks, little fighting, but occasional breakdowns

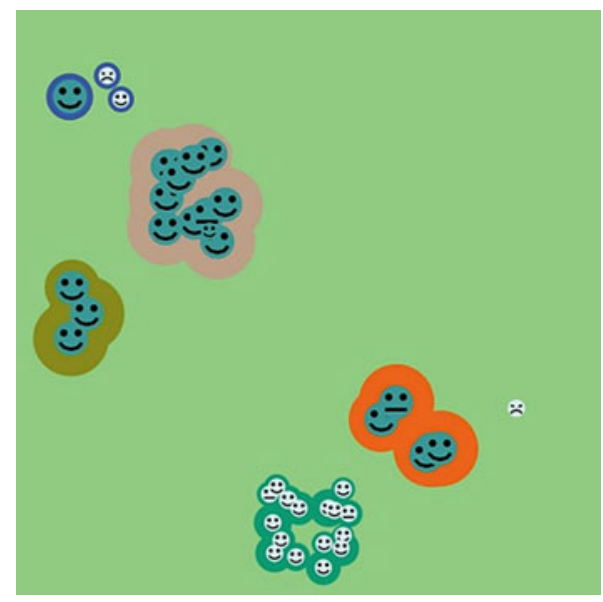

- Pattern 6d: high individualism (90), small power distance (10), medium xenophobia (0.2), low dyadic-trust-factor (0.1)

- Pattern 7e: high individualism (80), medium power distance (50), medium xenophobia (0.2), medium dyadic-trust $(0.3)$

Pattern a: Many long-standing groups Under low individualism, agents are likely to stay in groups. Large power distance further contributes to group stability by keeping low-status members in. Hence, many small groups created in tick 1 sustain themselves over time. Status differentiation occurs among agents within groups, due to fights.

Pattern b: Stable elite groups, volatile others Under high individualism, agents tend to leave the group easily. Even large power distance is not strong enough to stop them. Fewer but larger groups are formed, with clear status differentiation between them. If there is medium xenophobia, agents of high status tend to form all-elite groups with similar shade. These groups tend to be longer-lived than others, since other groups can be 'blown up' when they are colonized by an escapee from an elite group.

Pattern c: One happy group Without xenophobia, and under small power distance, highly individualistic agents generally form one single group, even when dyadic trust $=0$. Such a large group is stable over time and inclusive regarding different shades. There are hardly any fights. As a result, status differentiation occurs slowly, and the majority of group members are happy.

Pattern d: Nothing lasts for long This can occur when xenophobia is increased in parameter settings that show pattern c, regardless of power distance. High individualism plus small power distance makes it easy for agents to leave the group, so many agents are alone. The lack of trust also leads to less cohesive groups that do not last long. 
Pattern e: Happy segregation Figure 20.5 highlights one more pattern across time. Hierarchy establishes within 100 ticks, although not yet linked to shade. Gradually, fighting and group splitting has the side effect of coupling status with shade. Then, the system stabilizes as a 'class society'. The system remains metastable. Runs with the same settings but more shades often either default to pattern c or d.

Depending on settings and number of shades, other patterns obtain, e.g. smaller single-shade groups circling around large melting-pot groups, and various dynamics occur.

\subsection{Discussion and Conclusion}

GRASP world and culture Recognizable group life patterns are generated by a rather simple model based on foundational social scientific theory. They bring to mind societal patterns that are particularly apparent to people with cross-cultural experience.

Individualism: Perhaps counter-intuitively, individualistic agents find it easier to unite, because they can leave a prior group in which they received bad treatment. There are phases of chaos in a simulation run in which every agent moves around from one to the other. This allows the agents to self-organize until finding acceptable configurations. These could be status- or shade-sorted, depending on settings. There could be a parallel in the spontaneous forming and dissolving of all kinds of groups in individualistic societies, with usually limited lifetime.

Power Distance: The long-term patterns generated by status formation, in which initially stable groups become undermined, are interesting. If, in a real-world analogy, the status hierarchies were destroyed during such upheaval, this pattern could repeat itself, in analogy to revolutions and finite periods of stability following them. This is indeed what is argued by Turchin [22].

GRASP world, social identity and trust The number of 'norm meme' parameter values indicated by shade and perceived through xenophobia is sufficient to modify the base patterns from Fig. 20.4 considerably. This yields patterns a through e. Similar patterns can be recognized in group dynamics in organizations and societies. Experimenting with scale of norm difference and number of groups could lead to other plausible patterns.

The familiarity parameter for trust emanating from a group's age seems less interesting, since it just tends to freeze any pattern that occurs.

Interpreting the patterns A theory-based, content-free virtual world such as GRASP world cannot reproduce any specifics of any situation. Yet it can show the recurrent patterns in societies that are captured by Blaise Pascal's famous phrase 'Plus ça change, plus ça reste la même chose' (the more things change, the more they stay the same). Let us interpret the five patterns with some freedom 
of imagination. The various proximate mechanisms and value-laden words used in these interpretations are not implemented in GRASP world; but the idea is that they are all manifestations of status-power dynamics under cultural variation, and those two actually form the heart of GRASP world. So from a mental helicopter, we can recognize our real world in GRASP world.

Pattern a: many long-standing groups is characteristic of most societies in the world. Families or clans are long-lived almost everywhere. Only in Western societies, and more so in higher than in lower socio-economic classes, is there a lot of mobility between groups. If there are differences in social identities between subgroups, there will either be segregation, or the differences will be strongly suppressed.

Pattern b: stable elite, volatile others characterizes many societies with affluent elites and a large, rather impoverished, working class. The elite form stable networks and 'pass the ball to one another'. Temporary contracts force the working class into a volatile, often migratory existence, although they might, if given the chance, prefer to stay in pattern a.

Pattern c: one happy group describes societies in good times. Here we find the 'Global Village' metaphor enacted. This is particularly likely to happen in individualistic societies. For instance, at a major sports victory, or when a king is crowned, Scandinavian societies and the Netherlands feel like one happy family. Individualistic societies can also join in bad times and be 'happy' in terms of giving one another positive feeling or other forms of support.

Pattern d: nothing lasts for long characterizes individualistic societies in the absence of a reason for group solidarity. There is a lack of loyalty. Opportunism leads to volatile marriages, job-hopping and other forms of cross-group mobility in search of social status. Typical Western business practices of top-level executives or venture capitalists can show this pattern.

Pattern e: happy segregation has occurred and still occurs across religious or ethnic factions that coexist in the same society, but have inhibitions when it comes to mixing. In the Netherlands, these were called pillars, 'zuilen'. The two sexes could also coexist in this way to some degree.

We conclude that if a simulation requires human population with credible group dynamics over time, GRASP world citizens, given appropriate parameters, could fit the bill.

Further work Among myriad possible enhancements, these seem promising to us:

1. The model itself can be enhanced, e.g. with individual differences between agents, or with multicultural populations. Notably, differences in status worthiness (attractiveness) of agents, possibly including heterogeneity in perception ('beauty is in the eye of the beholder'), could alter the dynamics; or agents could differ in cultural traits within one run. 
2. The relationship between dimension of culture and model concepts can be further investigated. This includes thinking how other dimensions of culture could play a role [23]. However, adding model complicatedness exacerbates validation difficulties.

3. Cross-group status-power dynamics can be added. Here, dynamics between groups similar to those currently implemented between individuals could obtain; groups would also have a sense of social status worthiness and be motivated to use power if they felt they received too little status.

4. We could give the agents something to do. In other words, the model's mechanisms can be re-used for more targeted studies in more realistic simulated worlds that include context. This would yield an avalanche of richer concepts, for instance, on the mechanisms in Table 20.1, where a closer fit between model concepts and empirical attributes of the situation could be attempted. One such attempt has been made by giving the agents a common pool to govern. They have norms over how to use the resource. This shows intriguing emergent patterns.

The agents could reproduce, and culture could be modified across generations, based on a mix of parental and societal influence. This would open up a whole new area of research into culture's causes [24].

Conclusion It seems promising to develop GRASP world, as a tool for furthering the development of artificial sociality. It can throw light on societal dynamics and on group dynamics within societies. GRASP world agents could also be useful for researchers needing to populate their virtual world with simple, socially plausible virtual agents.

Acknowledgements The paper benefited from the comments of anonymous reviewers.

\section{References}

1. Hofstede, G., Hofstede, G.J., Minkov, M.: Cultures and Organizations, Software of the Mind. McGraw-Hill (2010)

2. Hofstede, G.J.: Culture's causes: the next challenge (distinguished scholar essay). Cross Cult. Manag. Int. J. 22(4), 545-569 (2015)

3. Gilbert, N., Conte, R.: Artificial Societies: The Computer Simulation of Social Life. University College London Press, London (1995)

4. Choi, K.S., Im, I., Hofstede, G.J.: A cross-cultural comparative analysis of small group collaboration using mobile twitter. In: Computers in Human Behavior, vol. 65, pp. 308-318, 2016/12/01/, (2016)

5. Kemper, T.D.: Status, Power and Ritual Interaction; A Relational Reading of Durkheim, Goffman and Collins. Ashgate, Farnham (2011)

6. Hofstede, G.J.: GRASP agents: social first, intelligent later. In: AI \& Society, pp. 1-9 (2017)

7. Deffuant, G., Carletti, T., Huet, S.: The leviathan model: absolute dominance, generalised distrust, small worlds and other patterns emerging from combining vanity with opinion propagation. JASSS. 16(1), (2013)

8. Grow, A., Flache, A., Wittek, R.: An agent-based model of status construction in task focused groups. J. Artif. Soc. Soc. Simul. 18(2), 4 (2015) 
9. Hemelrijk, C.K.: Simple reactions to nearby neighbors and complex social behavior in primates. In: Menzel, R.F., Fischer, J. (eds.) Animal Thinking: Comparative Issues in Comparative Cognition, pp. 223-238. MIT Press, Cambridge (2011)

10. Pretty, J.: Social capital and the collective management of resources. Science. 302(5652), 1912 (2008)

11. Wilson, D.S., Ostrom, E., Cox, M.E.: Generalizing the core design principles for the efficacy of groups. J. Econ. Behav. Organ. 90(S), 21-32 (2013)

12. Hofstede, G.J., Oosterkamp, E., Fritz, M.: Trust in the agri-food sector: a typology with a cultural perspective. In: Canavari, M., Fritz, M., Schiefer, G. (eds.) Food Supply Networks: Trust and E-business, p. 195. CABI, Wallingford (2016)

13. Hemelrijk, C.K.: The use of artificial-life models for the study of social organization. In: Thierry, B.S., Singh, M., Kaumanns, W. (eds.) Macaque Societies: A Model for the Study of Social Organization, pp. 295-313. Cambridge University Press, Cambridge (2004)

14. Minkov, M.: Cross-Cultural Analysis: the Science and Art of Comparing the World's Modern Societies and their Cultures. Sage, Los Angeles (2013)

15. de Mooij, M.: Global Marketing \& Advertising; Understanding Cultural Paradoxes, 5th Expanded edn. Sage (2018)

16. Martínez-Lozano, V.S.-M., José, A., Goudena, P.P.: A cross-cultural study of observed conflict between young children. J. Cross-Cult. Psychol. 42(6), 895-907 (2011)

17. Hofstede, G.J., Student, J., Kramer, M.R.: The status-power arena: a comprehensive agentbased model of social status dynamics and gender in groups of children. AI \& Soc. 1-21 (2018)

18. Nooteboom, B.: Trust: Forms, Foundations, Functions, Failures and Figures. Edward Elgar Publishing, Cheltenham (2002)

19. Brown, R.: Group Processes: Dynamics Within and Between Groups, 2nd edn. Blackwell, Malden (2000)

20. Hofstede, G.J.: "GRASP world" (Version 1.0.0). CoMSES Computational Model Library. Retrieved from: https://www.comses.net/codebases/f1089671-38da-4cca-88c5-711e936b2ada/ releases/1.0.0/ (2019, April 16)

21. Müller, B., Bohn, F., Dreßler, G., Groeneveld, J., Klassert, C., Martin, R., Schlüter, M., Schulze, J., Weise, H., Schwarz, N.: Describing human decisions in agent-based models ODD + D, an extension of the ODD protocol. Environ. Model Softw. 48, 37-48 (2013)

22. Turchin, P.: Historical Dynamics: Why States Rise and Fall. Princeton (2003)

23. Hofstede, G.J.: Theory in social simulation: status-power theory, national culture and emergence of the glass ceiling. In: Social Coordination: Principles, Artefacts and Theories, pp. 21-28, Exeter (2013)

24. Hofstede, G.J.: Culture's causes: the next challenge. Cross Cult. Manag. Int. J. 22(4), 545-569 (2015) 